\title{
THE EFFECT OF THE ADMINISTRATION SETTINGS OF PSYCHOMETRIC TESTS ON SELF-REPORTED SYMPTOM REDUCTION
}

\author{
Lediona Braho, Blerta Bodinaku \\ University of Tirana, Tirana, Albania \\ E-mail: lediona_braho@yahoo.com, bbodinaku@gmail.com \\ Dan Pokorny \\ Ulm University, Ulm, Germany \\ E-mail: dan.pokorny@uni-ulm.de
}

\begin{abstract}
Using psychometric measures as communication tools instead of automatic and mechanic tools to provide an immediate profile of the client, constitutes a relevant challenge in the domain of psychometric testing. Interventions in the psychometric measurement process can increase the utility of measures as potential therapeutic tools. The aim of this study was to investigate the effect of the measure administration setting in reducing self-reported symptoms. The administration setting was manipulated in respect to two factors: a) researcher-subject communication during the measure administration process, and b) information of the subject on the one-week retest procedure. The sample $(N=147)$ included four randomly assigned groups in $2 \times 2$ design. The group A was provided both interactive administration of the questionnaire and information about its repetition in the one-week-later retest; group $B$ was provided interactive administration without information about the retest; group $C$ conducted self-administration without the presence of the researcher, but information about the retest was provided; the control group D conducted self-administration only, with none of both interventions. The study has shown the effect of the researcher-subject communication; the CORE-OM values decreased significantly by the retest administration in groups $A$ and B. The study results support the understanding of the psychometrical measurement as a dynamical inter-personal process. Moreover, they provide a relevant hint for clinicians who can optimize the use of tests as potentially therapeutic tools.
\end{abstract}

Key words: administration effects, administration settings, CORE-OM, cross-cultural psychometry, self-report.

\section{Introduction}

\section{Administration of Psychotherapeutic Instruments}

Psychometric instruments, particularly self-report inventories, are of essential importance to the behavioral and medical research, as well as to the appropriate provision of mental health services. Most of the clinicians in mental health settings strongly rely on standardized diagnostic manuals when clinical diagnoses are required. However, although such manuals provide detailed criteria on setting diagnoses, they are not able to provide focus on the clients' subjective experience 
or to avoid clinicians' subjectivity in interpreting such personal experience. Therefore, the data which relies exclusively on the clinicians' judgment, even when guided by standardized diagnostic manuals are not necessarily as comprehensive and objective as generally expected.

As the complement and counter-part to the clinicians' judgement, the client's perspective was introduced by psychometric instruments through self-report questionnaires. The data acquired through psychometric measures come directly from the person being assessed (Schmitz et al., 2002), thus, providing a relevant advantage considering that symptoms are subjective experiences which cannot be measured in an objective way (Kendler, Gallagher, Abelson \& Kessler, 1996).

From the point of view of the measurement theory, this form of psychological assessment has been developed in order to satisfy the fundamental conditions of validity and reliability. These two important properties should differentiate psychometric measures from other clinical sources (Meyer et al., 2001).

From the practical point of view, self-report questionnaires are being appreciated as easy usable, widely applicable, economically acceptable, and statistically supported instruments (cf. Bagby, Wild \& Turner, 2003).

\section{Recent Development}

The end of the last century marked a major breakthrough of the testing paradigm (Finn \& Tonsager, 1992), with testing being considered as a relational experience carrying therapeutic potentials (Riddle, Byers \& Grimesey, 2002). Since then, the number of research findings which point at the administration effects has increased, however the main stream of practitioners and researchers still understand and use psychometric procedures as pure measuring (Bersoff \& Bersoff, 2000). Nonetheless, there is an increasing number of practitioners who advocate the use of psychological measures to be developed beyond the boundaries of an objective measure and to be perceived instead as an important tool to facilitate the treatment. Pokorny (2014) reminds Heisenberg's principle in physics telling that each measurement changes the observed object and points out that, analogously, the measuring by the psychometric questionnaire represents a therapeutic intervention. The clinician or researcher using a questionnaire should consider this by the decision and selection of psychometric instruments. Advocates of client-focused psychometric procedures suggest that the proper use of self-report measures can enhance client-clinician communication (Pokorny, Kulisek \& Vicari, 2012) and serve as a mini treatment per se (Meyer et al., 2001), or at least as an introduction to the process of psychotherapy (Knight, 1996). Further to this, they advocate to include the ethical perspective into the psychotherapy training and research, including psychometric procedures (Tschuschke, 2004).

In clinical settings, the psychometric assessment should add value to the treatment and management planning (European Federation of Psychologists Associations [EFPA] \& European Association of Work and Organizational Psychologists [EAWOP], 2005). A relevant aspect of the psychological testing is feedback, which is a dynamic and interactive process, part of the larger process of assessment (Pope, Butcher \& Seelen, 2000). A new approach to test feedback can replace a thoughtful discussion with the client of the results and their meaning. Oral feedback to a subject should be presented in a constructive and supportive manner (Pope, 1992).

The accuracy of self-reporting is affected by cognitive factors and related emotional processes. Inaccurate reporting can result due to several factors such as memory strategies or distortions (Stone, 2000), type of answering format (Sudman, Bradburn \& Schwarz, 1995), coding mistakes, due to the subject being unprepared for the self-report (Jobe \& Herrmann, 1996), manipulation of reporting (Bagby, Wild \& Turner, 2003) and social desirability (Worthington, 1986). Two cognitive processes which affect the process of self-report are self-focused attention (Stone, 2000) and self-monitoring (Mahoney, 2013). It is worth noting that inducing self-focus is widely considered as a tool which brings change in psychotherapy (Gibbons et al., 1985), but also can produce an increase of self-reported symptoms (Schmidt, Wolfs-Takens, Oosterlaan \& van den Hout, 1994). On the other hand, self-monitoring is found to produce reduction of anger, anxiety, guilt, isolation, and depression (Ajzen, 1985). 


\section{Context of the Study}

The development of mental health services has been going through a challenging path in countries of Eastern and South-Eastern Europe after the fall of communistic regimes. Mental health services in these countries share common challenges in introducing the multidisciplinary and community based approach versus the traditional psychiatry based one (Dlouhy, 2014). Similar challenges characterize the mental health services in Albania (Open Society Foundation for Albania [OSFA], 2012; Ministry of Health \& World Health Organization [WHO], 2005). Reporting the findings of a representative study with users of mental health services in Tirana, Bodinaku (2014) points that $60 \%$ of participants in the clinical sample did not receive any psychotherapeutic intervention, and most of the remaining clients received only some basic counseling/psycho-education. Moreover, it was observed that an average psychiatric interview lasted approximately 20 minutes, indicating a limited communication with the client.

\section{Study Focus}

Mental health services and assessment protocols are far more established in developed countries in Europe and other parts of the world, nonetheless the client-focused psychometric measuring does still constitute a challenge for well-established services as well. For example, professionals of mental health services in UK report to find psychometric measuring timeconsuming, burdening (Gilbody, House, Sheldon, 2002) and of no clinical relevance (Jacobs \& Moran, 2010) and therefore little attention is paid to providing communication and feedback to clients when psychometric procedures are involved (Pope, 1992).

\section{Methodology of the Study}

\section{General Background}

This study was motivated by the need for contextualized research in the mental health field in Albania, particularly in the domain of psychometric assessment given that standardized psychometric measures are only recently being introduced in the mental health services. Introducing and using psychometric measures in the mental health services in Albania represent several challenges which go beyond financial cost boundaries, including proper understanding of the utility of such measures, developing protocols of using self-report questionnaires, and including them into the assessment and follow up protocols of services. Such challenges can be addressed through research which focuses on finding ways to optimize the use of such measures in the clinical practice.

\section{Sample}

The study sample comprises students of the University of Tirana who participated in two repeated administrations. In the campus of the University of Tirana, which is the largest Albanian university, there live 4131 students, 3366 of them are women and girls. For the first administration, 200 students were recruited at the campus of the University of Tirana. The sample was recruited by a sequential asking of female students until the planned sample size was reached. There are clear limitations of the study representativeness with respect to the Albanian population: The participants were female students of the University of Tirana, who were present at the campus in the time of recruiting.

The 200 recruited participants were then assigned to four randomized, equally sized groups, each with 50 students. For the repeated second administration, 53 students were not accessible. 
The final sample consisted of $\mathrm{N}=147$ students $(73.5 \%$ or recruited students) divided into four randomized groups A, B, C, and D with 34, 31,39, and 43 participants respectively. All students were women, their age ranged from 18 to 25 years $(M=21.15 ; S D=2.11)$.

\section{Instrument}

In this study, we used CORE-OM, Clinical Outcomes in Routine Evaluation - Outcome Measure (Evans et al., 2002), as one of the self-report questionnaires recently translated, validated and standardized in Albania. The Albanian translation was supervised and authorized by the developer of the original instrument Chris Evans. CORE-OM comprises 34 items which are rated on a five point Likert from scale from "not at all" ( 0 points) to "all the time or most of the time" (4 points). This scoring order is reversed by eight resource oriented items. CORE-OM addresses four dimensions of psychological health: $\mathrm{W}$ - Subjective Wellbeing, P - Symptoms/ Psychological Problems, F - Functioning, and R - Risk. The first three subscales are summed up into the Non-Risk-Items subscale.

Higher scale scores indicate always higher problem severity. Particularly, higher scores in scales in Wellbeing and Functioning indicate deficits in these domains. CORE-OM has showed very good psychometric properties and high test-retest reliability (Evans et al., 2002). Similar findings were confirmed by the representative validation and standardization study in Albania (Bodinaku, 2014).

\section{Procedures}

The selection of the final sample required a preliminary screening of the student campus and receiving permission for the conduction of the study. As described above, the measure was administrated on four groups. The administration setting for the groups A and B comprised: (1) introduction to the questionnaire; (2) reading instructions; (3) psychological presence during the completion of the questionnaire. The latter implied supporting the subject to understand the items, hearing the subject's sharing and encouraging questions or comments on unclear items to the subject. The administration of the measure to group A also comprised (4) information on the retest after one week; this was not the case in the group B.

The subjects were contacted on individual basis at their living place in the student Campus. The tests in groups A and B were administered with the assistance of the psychological researcher who was present in each of the individual administrations providing interaction and information. The administration in the groups $\mathrm{C}$ and $\mathrm{D}$ was assisted by trained volunteers. It did not comprise any communication or interaction here; subjects were required to fill in the questionnaires without the presence of the researcher. According to the second experimental condition, students in groups $\mathrm{A}$ and $\mathrm{C}$ were informed about the one-week-later retest, while student in groups B and D were not. The questionnaire completion time varied from 15 to 45 minutes depending from the particular conditions of each administration procedure. The participants in communication based intervention groups were very prone to ask questions and share life stories or events, while completing the test.

\section{Data Analysis}

The data in this study were analyzed using the Statistical Package for Social Sciences (IBM SPSS), version 22.0. Pearson's correlations were performed to verify the test-retest reliability, by comparing observations in the first and second administration. By conducting paired sample t-tests, we explored differences of means for the first and second administration. Cohen's $d$ effect size was calculated to determine the magnitude of this difference. Aiming at group comparison concerning the changes between both administrations, the ANOVA model for $2 \times 2$ groups with repeated measures was applied including communication, information and change factors. 


\section{Results of the Study}

\section{Psychometry}

The analysis of the CORE-OM instrument in the total sample of $\mathrm{N}=147$ female students showed an excellent internal consistency with the same Cronbach's alpha value $(\alpha=.916)$ in both administrations; the test-retest correlation coefficient for the total sample was satisfactory as well $(\mathrm{r}=.646)$.

\section{General Effects}

Table 1 shows the two-way analysis of variance with repeated measures depicting the effects communication and information on the change between the first and the second administration. The first columns present the main effect change for the CORE-OM global scale and subscales. Summarized up over the four groups, there were significant test-retest changes in all scales but the last two ones. As it will be shown below, all significant changes were connected to the decrease of symptom severity and hence to the improvement of the self-estimation of the participants.

The interaction effects presented in the next table columns elucidate if there is a difference between the study groups concerning the magnitude of change. The interaction effect communication $\mathrm{x}$ change was significant by the global scale and particularly by the subscale Wellbeing. This indicated that students in the groups A and B communicating with the researcher during the administration could have generally better results on these scales than the other students in groups $\mathrm{C}$ and $\mathrm{D}$.

On the contrary, the interaction effect information $\mathrm{x}$ change was not significant on any scale. It means that for students in groups $\mathrm{A}$ and $\mathrm{C}$ who were informed about the second administration no better results were found compared to uninformed students in groups B and D. This suggests that information on the administration repetition only, does have "a healing effect".

Table 1. Influence of interventions on CORE-OM value changes.

\begin{tabular}{|c|c|c|c|c|c|c|c|c|}
\hline \multicolumn{4}{|l|}{$N=147$} & \multicolumn{5}{|c|}{ EFFECTS } \\
\hline \multicolumn{4}{|c|}{ Change } & \multicolumn{3}{|c|}{ Communication $\mathrm{x}$ change } & \multicolumn{2}{|c|}{ Information $\mathrm{x}$ change } \\
\hline CORE-OM & $F(1,144)$ & $p$ & & $F(1,144)$ & $p$ & & $F(1,144)$ & $p$ \\
\hline Global scale & 7.381 & .007 & $* *$ & 3.901 & .050 & * & .558 & .456 \\
\hline Non-risk & 7.287 & .008 & $* *$ & 3.879 & .051 & $\sim$ & .621 & .432 \\
\hline - Well being & 7.254 & .008 & $* *$ & 5.351 & .022 & * & .053 & .818 \\
\hline - Problems & 9.307 & .003 & $* *$ & 1.785 & .184 & & .355 & .552 \\
\hline - Functioning & .580 & .448 & & 2.667 & .105 & & 1.540 & .217 \\
\hline Risk & 2.009 & .159 & & .725 & .396 & & .007 & .935 \\
\hline $\begin{array}{l}\text { ANOVA model } \\
\text { change ... in th } \\
\text { communication } \\
\text { information ... }\end{array}$ & $\begin{array}{l}2 \times 2 \text { interve } \\
\text { DRE-OM sc } \\
\text { intervention } \\
\text { vention in }\end{array}$ & $\begin{array}{l}\text { on grout } \\
\text { betweer } \\
\text { groups } \\
\text { ips } A \text { ar }\end{array}$ & $\begin{array}{l}\text { and a } \\
\text { e firs } \\
\text { nd } B\end{array}$ & $\begin{array}{l}\text { nistration re } \\
d \text { second ad }\end{array}$ & $\begin{array}{l}\text { tion: } \\
\text { istration }\end{array}$ & & & \\
\hline
\end{tabular}

\section{Changes within Each Group}

Tables $2-5$ describe differences of means between administrations, effect sizes and statistical significance within each of four groups in regard to global scale of CORE-OM and its subscales. In groups A and B (tables 2 and 3 ) the test-retest correlation coefficient varied from moderate to high, with exception of the risk subscale which, as expected, showed in all four cases the lowest correlation coefficient, given the reactive and unstable nature of the risk behaviors in the nonclinical population. The wellbeing subscale in both cases showed moderate correlation coefficient. 
Groups $\mathrm{C}$ and $\mathrm{D}$ (tables 4 and 5) which had no communication during the administration showed

lower test-retest correlation coefficients compared to groups A and B.

Group A. The students in the group A were administered both with interaction and information about the one-week-later retest. The students in this group showed a statistically significant decrease of self- reported symptoms on Global scale level (Table 2). This significant decrease was significant particularly on the subscales of Well-being and Problems, while nearly no change was observed by the subscale of Functioning. It is worth noting that the subscale of Problems addresses symptoms (such as anxiety, depression, trauma and somatic symptoms).

Table 2. Changes within the group A with both interventions.

Group A ( $n=34)$

\begin{tabular}{ccccccccccc}
\hline CORE-OM & M1 & (SD1) & M2 & (SD2) & $\boldsymbol{d}$ & $\mathbf{r}$ & $\mathrm{pr}$ & $\mathrm{t}(33)$ & $\mathrm{pt}$ & \\
\hline Global scale & 1.02 & $(.45)$ & 0.92 & $(.31)$ & -.27 & .821 & .000 & -2.310 & .027 & $*$ \\
\hline Non-risk & 1.22 & $(.52)$ & 1.10 & $(.37)$ & -.25 & .835 & .000 & -2.253 & .031 & $*$ \\
- Well being & 1.38 & $(.75)$ & 1.15 & $(.56)$ & -.33 & .678 & .000 & -2.311 & .027 & $*$ \\
- Problems & 1.35 & $(.72)$ & 1.17 & $(.44)$ & -.30 & .724 & .000 & -2.051 & .048 & $*$ \\
- Functioning & 1.02 & $(.47)$ & 1.01 & $(.41)$ & -.03 & .736 & .000 & -.271 & .788 & \\
Risk & 0.12 & $(.22)$ & 0.07 & $(.18)$ & -.24 & .254 & .147 & -1.141 & .262 \\
\hline
\end{tabular}

$r$... Pearson's correlation coefficient, $p_{r}$... two-tailed significance

$d$... Cohen's effect size, $t(33)$... paired samples $t$-statistic, $p_{t} \ldots$ two-tailed significance

Group B. The students experienced the same intervention of the interactive communication as the students in the group A; they were not informed about the planned retest information nevertheless. In this group, the highly significant decrease on the global scale was observed, too, and moreover the significant to highly significant decrease on each subscales. The Well-being subscale showed the largest effect size $(d=-.67)$.

Table 3. Changes within the group B with the communication intervention.

\begin{tabular}{|c|c|c|c|c|c|c|c|c|c|c|}
\hline Group B (n=31) & & & & & & & & & & \\
\hline CORE-OM & M1 & (SD1) & M2 & $(S D 2)$ & $d$ & $r$ & $\mathrm{pr}$ & $t(30)$ & pt & \\
\hline Global scale & 1.06 & (.41) & 0.85 & $(.27)$ & -.59 & .862 & .000 & -5.124 & .000 & $* * *$ \\
\hline Non-risk & 1.26 & $(.47)$ & 1.03 & $(.32)$ & -.57 & .877 & .000 & -5.217 & .000 & $* * *$ \\
\hline - Well being & 1.45 & $(.66)$ & 1.08 & $(.43)$ & -.67 & .553 & .001 & -3.748 & .001 & $* * *$ \\
\hline - Problems & 1.37 & (.71) & 1.11 & $(.45)$ & -.43 & .890 & .000 & -3.861 & .001 & $* * *$ \\
\hline - Functioning & 1.08 & $(.29)$ & 0.93 & $(.25)$ & -.55 & .712 & .000 & -3.988 & .000 & *** \\
\hline Risk & 0.13 & $(.24)$ & 0.03 & $(.09)$ & -.53 & .015 & .936 & -2.093 & .045 & * \\
\hline
\end{tabular}

Groups $C$ and $D$. To students in the group C, the questionnaire was administrated in a "lonely setting" without the psychologist's interaction; they were just informed about the planned second administration in a week. The group D was a "pure" control group; nor communication neither information were provided. The test-retest correlations in both groups (Tables 4 and 5) were considerably lower than in previous groups indicating the self-estimation instability. The global scale and all subscales in both groups showed very small effect sizes. The pre-post differences in groups $\mathrm{C}$ and $\mathrm{D}$ were in no case statistically significant, indicating no reduction of symptoms in the second administration. 
Table 4. Changes within the group $\mathrm{C}$ with the information intervention.

\begin{tabular}{|c|c|c|c|c|c|c|c|c|c|}
\hline Group C $(n=39)$ & & & & & & & & & \\
\hline CORE-OM & M1 & (SD1) & M2 & (SD2) & $d$ & $r$ & pr & $\mathrm{t}(38)$ & $\mathrm{pt}$ \\
\hline Global scale & 1.20 & $(.51)$ & 1.18 & $(.48)$ & -.04 & .418 & .008 & -.253 & .802 \\
\hline Non-risk & 1.40 & $(.58)$ & 1.38 & $(.55)$ & -.04 & .446 & .004 & -.226 & .823 \\
\hline - Well being & 1.56 & $(.71)$ & 1.46 & $(.67)$ & -.16 & .352 & .028 & -.866 & .392 \\
\hline - Problems & 1.50 & $(.69)$ & 1.44 & $(.65)$ & -.10 & .455 & .004 & -.569 & .573 \\
\hline - Functioning & 1.25 & $(.55)$ & 1.30 & $(.55)$ & .09 & .424 & .007 & .537 & .594 \\
\hline Risk & 0.25 & $(.52)$ & 0.21 & $(.39)$ & -.07 & .169 & .303 & -.349 & .729 \\
\hline
\end{tabular}

Table 5. Changes within the group D with no intervention.

\begin{tabular}{|c|c|c|c|c|c|c|c|c|c|}
\hline Group D $(n=43)$ & & & & & & & & & \\
\hline CORE-OM & M1 & (SD1) & M2 & (SD2) & d & $r$ & $\mathrm{pr}$ & $\mathrm{t}(42)$ & pt \\
\hline Global scale & 0.92 & (.53) & 0.89 & $(.54)$ & -.05 & .694 & .000 & -.446 & .658 \\
\hline Non-risk & 1.10 & $(.62)$ & 1.06 & (.63) & -.05 & .711 & .000 & -.465 & .645 \\
\hline - Well being & 1.20 & $(.88)$ & 1.26 & $(.78)$ & .07 & .537 & .000 & .475 & .638 \\
\hline - Problems & 1.14 & $(.73)$ & 1.04 & (.71) & -.15 & .551 & .000 & -1.017 & .315 \\
\hline - Functioning & 1.02 & $(.56)$ & 1.02 & $(.62)$ & .01 & .793 & .000 & .120 & .905 \\
\hline Risk & 0.08 & $(.20)$ & 0.07 & $(.23)$ & -.02 & .190 & .223 & -.093 & .926 \\
\hline
\end{tabular}

Summarizing these results, the neutral but active presence of the psychological researcher communicating with students during the CORE-OM administration influenced the significant improvement of the symptom self-estimation by students in experimental groups A and B. Complementary to this, no analogous improvement was observed in the "lonely-setting" administration in groups $\mathrm{C}$ and $\mathrm{D}$.

\section{Discussion}

\section{Test-Retest Changes in Self-Reported Symptoms}

This study investigated the impact of the administration procedure on the reduction of the self-reported symptoms dependently on the approach used during the administration. Researchers and clinicians suggest that self-report questionnaires can facilitate the clinical communication (Pokorny, Kulisek \& Vicari, 2012), and can serve as potentially therapeutic intervention tools (Meyer et al., 2001). Results of this study showed that self-reported symptoms decreased in the second administration which was conducted one week later.

The reported symptoms, however, decreased in a statistically significant level, only for subject groups who were administered the questionnaire on a communication and interaction based approach. The control group which had no communication and no information on the retest showed the lowest mean difference between administrations, carrying no statistical significance.

In the validation and standardization study of the Albanian version of SCL-90-R and CORE$\mathrm{OM}$, researchers confirmed an excellent test-retest correlation coefficient; nevertheless, they found a significant decrease of reported symptoms (Bodinaku, 2014). Bodinaku related the symptom 
decrease with the emotionally supportive nature of the questionnaire administration process, as well as with cognitive factors which increase the accuracy of self-monitoring in the second administration.

\section{Intervention Effects}

In the here being presented study, the administration of CORE-OM to the groups A and B, included elements similar to the first psychotherapy/counseling session. Such elements include interaction and communication during the testing, as well as information about the second administration (second psychotherapy/counseling session). Similar studies have found that when testing and assessment is conducted in a relational context, it is followed by therapeutic effects such as reduction of symptoms (Meyer et al., 2001; Poston \& Hanson, 2010; Rosenthal, 2008). If measures are administered in a "vacuum" without interaction and communication between practitioner and client, measures remain simply tools for collecting information (Knight, 1996). It can be assumed that the process of testing intermediates the activation of emotional processes and serves as a socializing tool for the subject/client (Bersoff $\&$ Bersoff, 2000).

The reduction of self-reported symptoms can be also produced due to the activation of cognitive processes. In this study, we did not measure cognitive processes of the subjects; however, we intended to affect subjects' cognitions by manipulating subjects' attention. Thus, informing subjects on the one-week-later retest aimed at manipulating subjects' attention and mobilizing them on a cognitive level. Inducing self-focus is considered to be one of the change mechanisms in therapy (Gibbons et al., 1985), but can also lead to an increase of the reported symptoms (Schmidt, et al., 1994). On the other hand, self-monitoring can provide better explanation for the reduction of symptoms, as it leads to reduction of anger, anxiety, guilt, isolation and depression (Ajzen, 1985). Kanfer's feedback model (1970) suggests that self-monitoring has a reactive effect which leads to behavioral changes, once one knows he is being observed. Mahoney (2013) suggests that when people know they are being observed, they tend to monitor closer their behaviors and therefore they are more prone to change their behaviors. Nevertheless, it remains unclear the extent to which improved results are related to the repeated exposure to the test (Shapiro \& Cole, 1994). In our study, we could not confirm our expectation that informing subjects on the retest would focus their attention on their symptoms and produce reduced reported symptoms.

\section{Methodological Aspects}

Although the findings of this study support the main hypothesis that interaction based administration will be followed by significant decrease of symptoms, there remain several unresolved methodological aspects of this study. Contextual factors play a relevant influence in determining the final total score of a measure. It is possible to identify such factors, nonetheless it is difficult to consider them particularly in research settings. For example, there are limited chances to determine whether the subjects have overstated or if they have been open and honest (Stone, 2000). The awareness of being part of a research project can increase subjects' compliance with the expectations of the researcher, or expectations of a particular task (Worthington, 1986). Furthermore, preliminary information of the subjects may have affected cognitive processes of the subjects such as self-monitoring, or self-focus, nonetheless, no measurement of such constructs was performed. Processes and factors which may have influenced the symptomatic picture of the subjects, and which were not controlled by the researchers or subjects, may be many. Another testing could be necessary to provide additional data to support the sustainability of such changes.

\section{Current Challenge}

Mental health services in developed countries in Europe and other parts of the world are currently confronted with economical and organizational requirements, followed by considerable changes in the nature of the clinical work and namely its time structure. The time effectiveness and economical outcome parameters play the leading role by the management of the treatment in 
mental health institutions. The self-administration of psychometric instruments by paper-and-pencil is being outranged in favor of the direct computer administration. It is being pointed out that the results of both administration methods are fully comparable and that the PC-administration saves a considerable amount of time for mental health staffs. Indeed, both are true. However, the usual clinical setting of administration corresponds to the "lonely" administration in our control group D. Results achieved by our guided study groups A and B suggest that the time and relationship engagement spent during the accompanied questionnaire answering can be worth. These issues ask for consideration particularly in countries which are currently working on their orientation for the psychometrical theory and practice.

\section{Conclusions}

This study aimed at investigating the effects of the measures' administration setting in selfreported symptoms reduction, in a period of one week. The manipulation of the administration setting was based on researcher - subject interaction during the administration, and informing about the retest to be conducted. Four study groups were exposed to different administration conditions, namely: group $\mathrm{A}$ - interaction and information, group B-interaction only, group $\mathrm{C}$ - information only, and group D - control group. In line with the aim of the study, the researchers expected symptoms to decrease in the second administration of CORE-OM for three study groups (A, B and C), but not for the control group (D). The hypothesis was confirmed for group A, B with moderate and high effect sizes. No significant mean differences and effect sizes were found for group $\mathrm{C}$ and the control group (D). These findings suggest that when the psychometric measurement is conducted in a relational setting, it can be followed by decrease of symptoms.

Standardized measures are widely used in the clinical practice as well as research tools. In the clinical practice, the communication, interpretation, and information of the client can facilitate the client-clinician communication. When conducting research in mental health settings, the communication based use of measures can facilitate the accuracy of self-reporting, leading to improved evaluation of users in mental health settings. In addition, the findings of this study suggest researchers and clinicians to take into consideration various factors of the administration process and setting which may affect the accuracy of the reporting, as well as can bring value to the therapeutic relation with the client. Therefore, training of mental health professionals and researchers in the field is necessary in order to provide them with the best practices of psychometric measurements.

\section{References}

Ajzen, I. (1985). From intention to actions: A theory of planned behavior. In J. Kuhl, \& J. Beckman (Eds.), Action-control: From Cognition to Behavior (pp. 11-39). Heidelberg: Springer.

Bagby, M. R., Wild, N., \& Turner, A. (2003). Psychological assessment in adult mental health settings. In J. R. Graham, \& J. A. Nagilieri (Eds.), Handbook of psychology: Assessment psychology 10 (pp. 213-234). New Jersey: Wiley \& Sons.

Bersoff, D. M., \& Bersoff, D. N. (2000). Ethical issues in the collection of self-report data. In A. A. Stone, J. S. Turkkan, C. A. Bachrach, J. B. Jobe, H. S. Kurtzman, \& V. S. Cain (Eds.), The science of self report: implications for research and practice (pp. 9-25). New Jersey: Lawrence Erlbaum Associates.

Bodinaku, B. (2014). Translation, validation and standardization of the Albanian version of the SCL-90-R (Symptom Checklist-90-Revised) and CORE-OM (Clinical Outcomes in Routine Evaluations - Outcome Measure). (Unpublished doctoral dissertation.) Vienna: Sigmund Freud Private University.

Dlouhy, M. (2014). Mental health policy in Eastern Europe: A comparative analysis of seven mental health systems. BMC Health Services Research, 14 (1), 1-8.

Evans, C., Connell, J., Barkham, M., Margison, F., McGrath, G., Mellor-Clark, J., \& Audin, K. (2002). Towards a standardized brief outcome measure: psychometric properties and utility of the CORE-OM. British Journal of Psychiatry, 180 (1), 51-66. 
European Federation of Psychologists Associations and the European Association of Work and Organizational Psychologists (2005). European Test User Standards for test use in Work and Organizational Settings. Retrieved on November 2015, from http://www.efpa.eu/proffesional-development/tests-and-testing.

Finn, S. E., \& Tonsager, M. E. (1992). The therapeutic effects of providing MMPI-2 test feedback to college students awaiting psychotherapy. Psychological Assessment, 4 (3), 278-287.

Gibbons, F. X., Smith, T, W., Ingram, R, E., Pearce, K., Brehm, S. S., \& Schoreder, D. J. (1985). Self-awareness and self-confrontation: Effects of self-focused attention on members of a clinical population. Journal of Personality and Social Psychology, 78, 662-675.

Gilbody, S., House, A., \& Sheldon, T. (2002). Psychiatrists in the UK do not use outcome measures. British Journal of Psychiatry, 180 (2), 101-103.

Jacobs, R., \& Moran, V. (2010). Uptake of mandatory outcome measures in mental health services. The Psychiatrist, 34, 338-343. doi: 10.1192/pb.bp.109.026526

Jobe, J. B., \& Herrmann, D. J. (1996). Implications of models of survey cognition for memory theory. In D. Herrmann, M. Johnson, C. McEvoy, C. Hertzog, \& P. Hertel (Eds.), Basic and applied memory: Research on practical aspects of memory (pp. 193-205). Hillsdale, NJ: Lawrence Erlbaum Associates.

Kanfer, F. H. (1970). Self-monitoring: Methodological limitations and clinical applications. Journal of Consulting and Clinical Psychology, 35, 148-152.

Kendler, K. S., Gallagher, T. J., Abelson, J. M., \& Kessler, R. C. (1996). Lifetime prevalence, demographic risk factors, and diagnostic validity of non-affective psychosis as assessed in a U.S. community sample: The National Comorbidity Survey. Archives of General Psychiatry, 53 (11), 1022-1031.

Knight, B. G. (1996). Psychotherapy with the older adult (2nd Ed.). Thousand Oaks, CA: Sage.

Mahoney, C. (2013). Self-monitoring to enhance the effectiveness of a treatment for anxiety. Counseling Psychology Dissertations. Boston: Northeastern University. http://hdl.handle.net/2047/d20003251

Meyer, G. J., Finn, S. E., Eyde, L. D., Kay, G. E., Moreland, L. L., Dies, R. R., Eisman, E. J., Kubiszyn, T. W., \& Reed, G. M. (2001). Psychological Testing and Psychological Assessment. A Review of Evidence and Issues. American Psychologist, 56 (2), 128-165.

Ministry of Health of Albania \& World Health Organization, (2005). Operational plan for mental health services development in Albania. Tirana: MoH-Who.

Open Society Foundation for Albania (2012). Assessment of mental health care needs at national level. Tirana: Author.

Pokorny, D. (2014). Psychometrische Befragung [Psychometric administration]. In C. Lenk, G. Duttge, \& H. Fangerau (Eds.), Handbuch Ethik und Recht der Forschung am Menschen [Handbook on Ethics and Law of Research Involving Human Subjects] (pp. 87-91). Berlin, Heidelberg: Springer.

Pokorny, D., Kulisek, R., \& Vicari, A. (2012). On questionnaires and clients: What was earlier - scale or item? In Book of Abstracts. The 3rd joint Meeting of the SPR European und UK Chapters (pp. 61-62), SPR: Porto, Portugal.

Pope, K. (1992). Responsibilities in providing psychological test feedback to clients. Psychological Assessment, 4 (3), 268-271. http://dx.doi.org/10.1037/1040-3590.4.3.268

Pope, K. S., Butcher, J. N., \& Seelen, J. (2000). The MMPI, MMPI-2, and MMPI-A in court: Assessment, testimony, and cross-examination for expert witnesses and attorneys, Second Edition. Washington, DC: American Psychological Association.

Poston, M. J., \& Hanson, E. W. (2010). Meta-analysis of Psychological Assessment as a Therapeutic Intervention. Psychological Assessment, 22 (2), 203-212.

Riddle, B. C., Byers, C. C., \& Grimesey, J. L. (2002). Literature review of research and practice in collaborative assessment. The Humanistic Psychologist, 30 (1-2), 22-48.

Rosenthal, R. (2008). Science and ethics in conducting, analyzing and reporting psychological research. In D. N. Bersoff (Ed.), Ethical conflicts in psychology, 4th ed. (pp. 390-394). Washington DC: American Psychological Association. 
Schmidt, A. J. M., Wolfs-Takens, D. J., Oosterlaan, J., \& van den Hout, M. A. (1994). Psychological mechanisms in hypochondriasis: Attention-induced physical symptoms without sensory stimulation. Psychotherapy \& Psychosomatics, 61, 117-120.

Schmitz, N., Hartkamp, N., Franz, M., Buse, S., Karig, R., \& Tres, W. (2002). Properties of the Symptom Check List (SCL-90-R) in a psychosomatic consultation-liaison setting. Psychological Reports, 90, 1201-1207.

Shapiro, E., \& Cole, C. (1994). Behavior change in the classroom: Self Management interventions. New York, NY: Gifford Press.

Stone, A. A. (2000). The Science of Self-report: Implications for research and practice. Mahwah NJ: Lawrence Erlbaum Associates, Inc.

Sudman, S., Bradburn, N., \& Schwarz, N. (1995). Thinking about answers: The application of cognitive processes to survey methodology. San Francisco: Jossey-Bass.

Tschuschke, V. (2004). Zur Ethik in der psychotherapeutischen Ausbildung und Psychotherapieforschung [On ethics in the psychotherapy training and research.]. In M. Bormuth, \& U. Wiesing (Eds.), Ethische Aspekte der Forschung in Psychiatrie und Psychotherapie [Ethical aspects of the psychiatry and psychotherapy research.] (pp. 43-53). Köln: Deutscher Ärzte-Verlag.

Worthington, E. L. (1986). Client compliance with homework directives during counseling. Journal of Counseling Psychology, 33 (2), 124-130.

Advised by Stanislava Yordanova Stoyanova, South-West University "Neofit Rilski", Bulgaria

Received: November 10, 2015

Accepted: December 12, 2015

\begin{tabular}{cl}
\hline Lediona Braho & $\begin{array}{l}\text { M.Sc., Assistant Lecturer, University of Tirana, Faculty of Social Sciences, } \\
\text { Department of Pedagogy and Psychology, Bulevardi Gjergj Fishta, Tirana, } \\
\text { Albania. } \\
\text { E-mail: lediona_braho@yahoo.com }\end{array}$ \\
\hline Blerta Bodinaku & $\begin{array}{l}\text { Dr., Senior Lecturer, University of Tirana, Faculty of Social Sciences, } \\
\text { Department of Pedagogy and Psychology, Bulevardi Gjergj Fishta, Tirana, } \\
\text { Albania. } \\
\text { E-mail: bbodinaku@gmail.com }\end{array}$ \\
\hline Dan Pokorny & $\begin{array}{l}\text { Doc. Dr., Private Docent, Ulm University, Medical Faculty, Psychosomatic } \\
\text { Medicine and Psychotherapy, Albert-Einstein-Allee 23, D-89081, Germany. } \\
\text { E-mail: dan.pokorny@uni-ulm.de }\end{array}$ \\
\hline
\end{tabular}

